\title{
COMMUNICATION MODELING: CONSIDERING COMPLEXITY IN DIGITAL TECHNOLOGY POLICIES
}

\author{
Modelagem de comunicação: considerando a complexidade em políticas de \\ tecnologias digitais
}

Modelado do comunicación: considerando la complejidad en políticas de
tecnologías digitales

Giovanni Moura de Holanda Research Fellow - CTI Renato Archer gmholanda@yahoo.com.br

\author{
Angela Maria Alves \\ Researcher - CTI Renato Archer \\ angela.alves@cti.gov.br
}

\begin{abstract}
Policies related to digital technologies tend to scarcely consider comprehensive communication models and the way information is actually generated and assimilated in a communicational process. Typically, models that describe communication are completely circumscribed by the technical dimension. In technology-mediated interaction, the effectiveness between the intention of a message and how it is received and understood by a user is fundamental to knowledge creation and the construction of intersubjectivity, and can be decisive in ICT policies. Interactivity, multiple contexts and subjectivity are conditioning factors of this complex process. This paper presents a reflection on how communication models including these factors can contribute to a phenomenological understanding of communication, covering gaps of modeling usually adopted, whose focus is predominantly on the technological or mass communication dimension. A broader and multidimensional understanding of the inherent complexity of communicational processes may more efficiently support the formulation of digital technology policies.
\end{abstract}

Key words: Communication model. Media culture. ICT policies.

\section{Resumo}

Políticas voltadas a tecnologias digitais raramente tendem a considerar modelos de comunicação abrangentes, tampouco o modo como a informação é realmente gerada e assimilada em um processo comunicacional. Normalmente, os modelos que descrevem a comunicação são inteiramente circunscritos pela dimensão técnica. Em interações mediadas pela tecnologia, a efetividade entre a intenção de uma mensagem e como ela é recebida e compreendida por um usuário é fundamental para a criação de conhecimento e a construção de intersubjetividades, e pode ser decisiva em políticas de TIC. Interatividade, múltiplos contextos e subjetividade são fatores condicionantes desse processo complexo. Este artigo 
apresenta uma reflexão sobre como modelos de comunicação que incluem esses fatores podem contribuir para o entendimento fenomenológico da comunicação, cobrindo lacunas de modelagens usualmente adotadas, cujo foco atém-se predominantemente à dimensão tecnológica ou de comunicação de massa. Uma compreensão mais ampla e multidimensional da complexidade inerente ao processo comunicacional pode suportar com maior eficiência a formulação de políticas de tecnologias digitais.

Palavras-chave: Modelo de comunicação. Cultura de mídia. Políticas de TIC.

\section{Resumen}

Las políticas orientadas a las tecnologías digitales raramente tienden a considerar modelos de comunicación exhaustivos, ni tampoco la forma en que la información es realmente generada y asimilada en un proceso de comunicación. Normalmente, los modelos que describen la comunicación están enteramente circunscritos por la dimensión técnica. En las interacciones mediadas por la tecnología, la efectividad entre la intención de un mensaje y cómo es recibida y entendida por un usuario es fundamental para la creación de conocimiento y la construcción de intersubjetividades, y puede ser decisiva en políticas de TIC. La interactividad, los múltiples contextos y la subjetividad son factores condicionantes de este proceso complejo. Este artículo presenta una reflexión sobre cómo los modelos de comunicación que incluyen estos factores pueden contribuir al entendimiento fenomenológico de la comunicación, que cubren las lagunas de modelos usualmente adoptados, cuyo foco se atiene predominantemente a la dimensión tecnológica o de comunicación de masa. Una comprensión más amplia y multidimensional de la complejidad inherente al proceso de comunicación puede soportar con mayor eficiencia la formulación de políticas de tecnologías digitales

Palabras clave: Modelo de comunicación. Cultura de los medios. Políticas de TIC.

\section{INTRODUCTION}

In the evolution of communication systems, including the transmission range in terms of distance and topology (point-to-point, mass communication, point-multipoint, global or local, for example) and all technological leaps, some innovations have brought considerable impacts on all actors involved. Among the technical advances, we can mention the fusion of sounds and images, intercontinental and satellite communication, digitization and digitalization, optics and laser, multimedia, internet, smartphones, social networks, internet of things.

In turn, such movements have motivated radical and high-impact innovations such as interactivity during the act of content fruition, mobility and ubiquity of communication, high definition, and technological convergence, especially in intelligent devices for individual use - the contemporary interfaces such as tablets and smartphones. Convergence, in fact, 
combines innovations and knowledge, being therefore a trend related to several activities in the human ecosystem.

Such innovations have implications in cognitive processes underlying human perception and in relational and social processes, which make more evident the circularity of information and the asymptotic increase of the presence of information and communication technologies (ICT) in people's daily life. Researching into social and psychological effects of these factors by means of strictly technology-oriented linear models is not minimally compatible with the complexity involved.

Technological and media convergence imply complex issues in both technical and economic issues as well as in the social, political and cultural dimensions. On the one hand, digitization imposes regulatory impairments, for example, services that previously relied on a unique technological infrastructure are now being provided over other networks, alone or in combination with other service platforms - see, for example, (BAR; SANDVIG, 2008). On the other hand, convergence highlights intermedia exchanges and interferences, with questions regarding semiotic translation (see, for example, PLAZA, 2003), enhancing intersubjectivities, cultural hybridity, and, at another extreme, unprecedented individualization in the establishment of demand for content.

In any case, old rules and policies need to be adjusted and often substantially reformulated in order to regulate the interests at stake and deal with the inherent complexity in disruptive technologies and in the subsequent mediatic reorganization. In addition to the issues that orbit around the boundaries of policies on telecom, broadcast or broadband, there are those that address industrial innovation and those that are even more multisectoral and interdisciplinary, such as policies related to content production, education ( $c f$. LAURETH, 2014), digital inclusion, personal privacy and commercial security ( $c f$. MANSELL, 2016).

Taking this scenario as a backdrop, this paper seeks to revisit some of the concepts and models associated with communication, in its broadest and most general form, bringing them to a reflection in the light of the complexity of new technologies and media convergence. Digital technologies intensify the effects caused by communication media, amplifying the circularity of information and introducing elements that open new perspectives of individual and collective experience. At the same time, convergence and the technological pace of chance reveal unwanted aspects that need to be taken care of, including personal data invasion, cyberattacks, post-truth and false news, cultural alienation, digital divide and social exclusion. 
These effects reflect the underlying complexity of such a process, which need to be reflected in the public policies focused on ICT, audiovisual and educational sectors, to name a few. It is therefore necessary to consider it systemically, in terms of its inherent complexity, focusing on many variables and in the multiple contexts to understand the scope and impacts of local and global communication being practiced today. It is with this gaze, more investigative than propositional, that we weave the present reflection.

The outline to lead the mentioned reflection is formed by the mediatic fusion of sounds and images in digital format, associated with the interactivity in the content consumption and the mobility of fruition, with the features provided by the technological convergence. Thus, we consider both the factors provided by mass communication and digital culture, including the imbrications that marked the transition between them and that shaped the intermediate phase called by Lucia Santaella as "media culture", in her historical vision on the coexistence and convergence of the media (2003). In the perspective of this author, about which we share and in a certain way try to follow on this reflection, the various types of signs that circulate through the transmission media are capable of shaping the thought and human sensibility and also foster new socio-cultural contexts (2003, p. 13).

The methodological course that allows us to develop the reflections proposed in this paper begins when we revisit some approaches of modeling through its historical and epistemological perspective: from linear to circular model. Next, we focus on typical aspects of digitally mediated societies that characterize the current complexity of the communication process and that should be considered in multidimensional modeling. Among these aspects are the technological and media convergence, the content production and reception logic, interactivity and circulation of the information, media and cultural identity, global versus local content. With the characteristics of this current scenario in evidence, we discuss a type of modeling that, based on principles of complexity theory, allows us to deepen the knowledge related to the impacts of emergent technologies and new communicational habits on society, as well as the importance of considering these trends in formulating policies for the digital ecosystem. 


\section{A STARTING POINT: FROM LINEAR TO CIRCULAR MODEL}

Is there a single model able to describe communication comprehensively? This question is not simple and may be addressed by several initial points. We propose to start thinking about some of them.

Mass media and communication in general reach a very large portion of the global population and its impacts are constantly under study. Digitization, new services and convergent devices have amplified and deepened such impacts with unprecedented factors, making human and cultural consequences still more significant. Communication modeling may help to understand this scenario and, if we consider digital media, it is particularly significant in terms of content production, education services (e-learning) and e-inclusion initiatives.

Before this scenario was a reality, Claude Shannon presented a contribution that was a milestone in the development of information theory. It was encompassed in a linear model of communication, with a strong mathematical background and constituted by the well defined phases of emission, distribution and reception of a message - the Shannon and Weaver communication model (1949). This model embodied several seminal concepts, such as information as function of the degree of entropy (the amount of uncertainty involved in the communication), probability of error, information redundancy, and channel noise.

With this model it was possible to "quantify" the information, and although it was generated within the paradigms of the scientificity of exact sciences, it made possible a cultural exchange between different disciplines (MATTELART; MATTELART, 1999). As these authors point out, for example, there is a mutual association between Shannon and Biology. The former was inspired to a certain extent in the biology of the nervous system, and, in turn, the mathematics of its model contributed to advances of molecular biology.

The Wiener model, whose ideas and principles were published concomitantly with that of Shannon in 1949, incorporates the circularity of information and presents the bases of what he called cybernetics, based on the feedback of the message ${ }^{1}$. Also with multidisciplinary repercussions, this conception extrapolated the technological sphere and reached other fields of knowledge, such as Biology, Sociology and Psychology. For Wiener, society can only be

\footnotetext{
${ }^{1}$ A scenario of the circumstances surrounding these works, including the interrelation between both authors and the multidisciplinary group constituted to discuss and understand these new ideas, is presented in (GLEICK, 2011).
} 
understood through the study of messages and the available communication elements ([1951] 1960).

The mathematics underlying the Shannon and Weaver model (1949) included the noises inherent to the communication process, but did not emphasize the semantic noises or the semiotic principles of an information source, neither the interaction that presides over its construction and emission, nor the meaning attributed by the receiver of the message. The presence of communication noises - both of physical and mechanical nature, the channel noise, and of semantic and psychological nature - prevents isomorphism between the sender and receiver.

These efforts to model communication and to ground an information theory stimulated researchers from various fields to address the challenge. The imposed challenge was to arrive at a unified model contemplating the channel noises, the semantic noises and the circularity of the information - the feedback. Channel noise refers to interference in the transmission of the message, semantic noises correspond to incomprehension of the message, and feedback comprises the actions to properly understand the message (NARULA, 2006).

In tune with the zeitgeist that then motivated the communication studies, Wendell Johnson presented a model (1951) that tried to include such semantic aspects. This model considers the context and the fact that the stages of communication are interrelated in a continuous process. Although not yet fully describe the communication process, it served as a basis for later models to go beyond this intention (NARULA, 2006) ${ }^{2}$.

\section{MODELING DIGITALLY MEDIATED SOCIETIES}

The process of circularity and feedback intensified by interactivity and digital technologies leads to a deepening of intersubjectivity, to the re-signification of the very transmitted information and to an expansion of intelligence technologies (LÉVY, 1993). Associated with these effects, one can add the importance of images in the languages that prevail in media culture. In a super-connected society, multimedia technologies and the mixing of forms of expression and means of distribution and informational interaction

\footnotetext{
${ }^{2}$ Several communication models have been developed in order to explain how information is transmitted and received between two points, machine or humans, and to identify and measure the factors affecting the efficiency of such a process. A number of handbooks and tutorials address this matter and provide these models in details (for instance, NARULA, 2006; MCQUAIL; WINDAHL, 1993).
} 
(SANTAELLA, 1993) shift our cognitive experience to new domains - from the virtual, including the Baudrillardian illusion, up to re-signification of messages and to the fast acquisition of knowledge.

Convergent devices and the inextricable fusion of TV, computer and internet empowers this scenario, bringing multimedia content to the entire connected society. And more, content formatted as "intelligent" combination of texts, sounds and images, in high definition, with interactivity, in real time and customized. Understanding these factors in deep becomes a need and huge challenge. For the present reflections, we thus propose to visit some points of this convergent environment, in search of more understanding.

\subsection{Big and very small screens: the world in sound and images}

Information in sound and image sequences is at the heart of digital communication processes. In accordance to most recent Ofcom report, images are becoming an increasingly central method of communication, in such a way that more than $60 \%$ of people in the UK say they post images and video online (OFCOM, 2017).

Content and applications (apps) in all screen sizes (be it in any internet-enabled device, for instance, smartphone, laptop, television or cinema) and transiting between different media, including traditional telephony, transmit some amount of information encoded in sound or image or in a combination of both. High-Definition standards for video and audio (e.g., Ultra HD 4k and digital surround sound formats, in TV set, or Cinema 3D, in big screen projections) imply in additional impacts on sensorial perceptions.

As products of fruition, such media have at least two interrelated dimensions: technological - associated with the form how information is "encompassed" and exhibited and social, since they are able to provide information and entertainment to people, individual or massively. Consequently, the respective communication processes are influenced by two kinds of noise: physical and psychological.

At a first glance, image and sound may be directly related to sensory perception and the instant triggering of cognitive processes, opening the gates to the subsequent interaction between a transmitter and a receiver. Interactivity, in turn, deepens such a possibility and makes receivers able to adjust the message, in order to improve comprehension, and to some extension, making them able to participate in content creation. In this case, receivers assume a persona, becoming active users. 
By focusing communication from two perspectives - social and technical - it is important to note that their theoretical models maintain a narrow dialogue concerning mediated interaction. From a technical point of view, communication theory is strictly concerned with separate steps of a signal transmission-reception process, as shown in Figure 1. The lower three blocks at the bottom of the diagram illustrates such a process: emitter, medium and receiver.

Moving into a more complex approach, the same process may assume other dimensions and encompass the content to be transmitted in terms of its production and reception contexts, as depicted by the upper part of this figure. Reception is therefore expanded to consider the techno-cognitive and subjective aspects, which are multidisciplinary in nature, requiring knowledge of sociology, neuroscience, anthropology and psychology, for instance.

Similarly, the emission stage is enlarged in order to consider the content creation and intentionality that drives such a creation. Both extremes in the social communication process - intentionality and subjectivity - are therefore influenced by the political, cultural and socioeconomic contexts. From a sociologic perspective, the interferences on the reception side may be visualized beyond the individual sphere, reaching the group behavior and being associated with a socialized subjectivity, as in Bourdieu's concept of habitus adopted in his social theory.

However, both intentionality and subjectivism are addressed by a field of study that lies between semiology and philosophy of mind and consequently falls out of the scope of this short description. Even without deepening in these disciplinary fields, it is possible to generically perceive that communicative intention has several impacts on media interpretation, for instance, in the words of Zegarac "miscommunication may also arise because some evidence of the communicative intention has not been recognized by the addressee" (2007). On the other hand, some researchers argue that due to globalization effects there is common ground for audience interpretation across cultures; but there are also those who believe that cultural context influences audience reception (HINTON, 2007). From our perspective - as well as others, pointed out further ahead -, the latter argumentation is more adherent to what experience in this area has revealed (cf. HOLANDA et al., 2008).

Indeed, between the intention to convey an idea, its transformation into symbols and the trustworthy meaning at the reception, there is a long semiotic path. The long distance between intentionality on the one hand and subjectivity on the other has motivated several 
studies and finds a rather inspiring parallel in Bergson. In his Introduction to Metaphysics (1974), in saying the latter is a science that intends to forgo symbols, he opened a wide perspective on the effectiveness of communication.

To some extent, Bergsonian epistemology points out that we constantly misunderstand each other in communication processes, due to our incapacity to enter into someone else's mind. Even in the face of this apparent insurmountability, the underlying theory of his concepts of duration and intuition ${ }^{3}$ may remove such an obstacle and provide conditions to a more favorable intersubjectivity between communicating beings or, from a technical viewpoint, between emitters and receivers ${ }^{4}$.

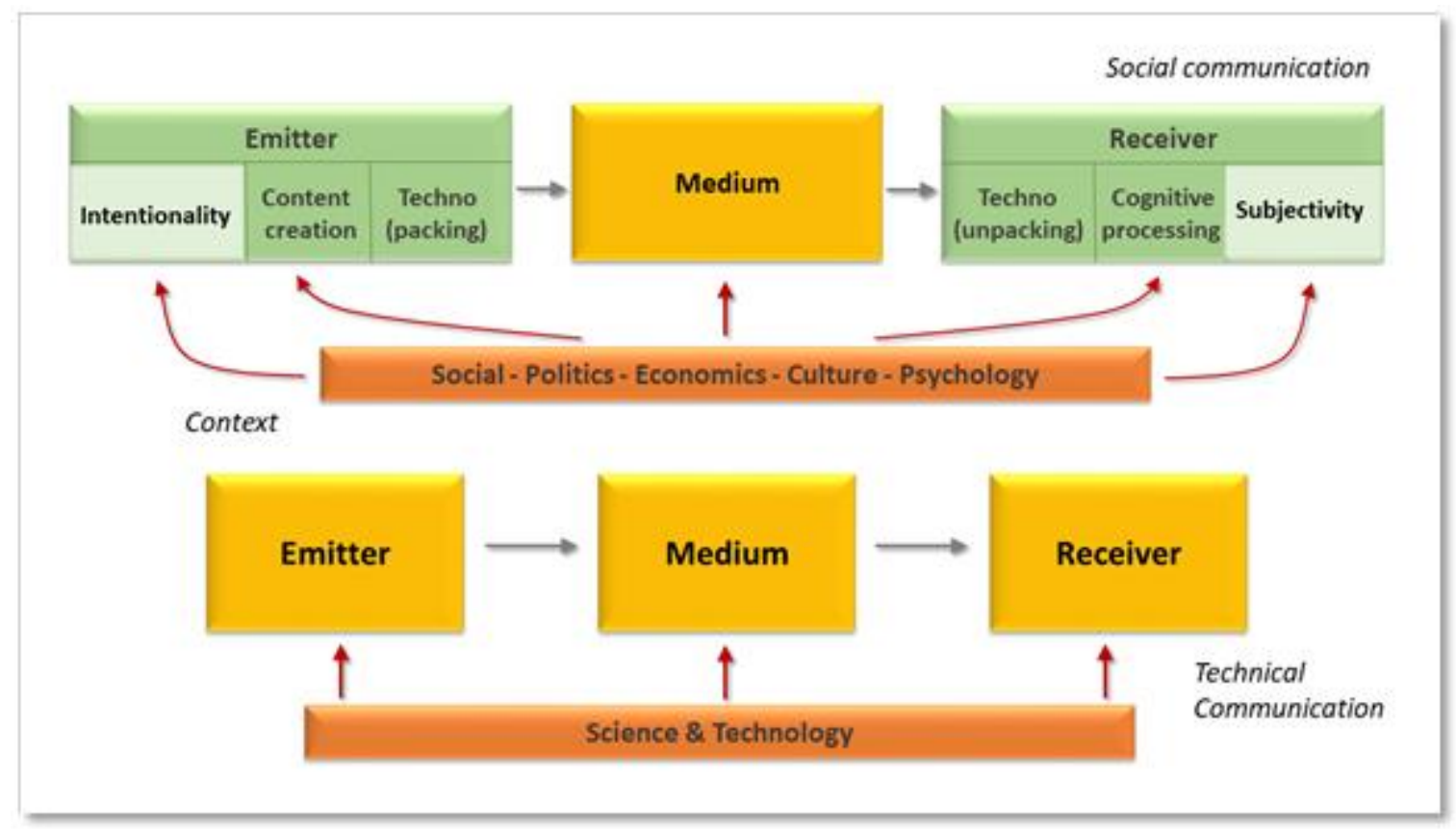

Figure 1 - Decomposing communication into two perspectives: social and technical

Source: Authors' own elaboration

In Figure 1 representation, the social communication process was decomposed into activities normally observed in the productive chain of contents in general, such as programming and distribution (associated with the technological platform, e.g., terrestrial broadcasting, satellite, cable or mobile). Although not represented in this pictorial scheme, the

\footnotetext{
${ }^{3}$ In a word, the term "duration" is applied here in the sense of "to flow" over time, leading to an uninterrupted process of change; and "intuition", as a method of apprehending the mobility associated to duration itself - for a more detailed description of concepts, see, for example, "Introduction to Metaphysics" by Bergson, published originally in Revue de Métaphysique et de Morale, in 1903 (BERGSON, 1974).
}

${ }^{4}$ A detailed reflection about this Bergsonian perspective on communication is found in (FELL, 2009). 
technical communication technology is also modeled by this context, since the science and technology progress depends on the same context. Also, the reception technical conditions, as well as of the content production, exerts influence on the user's cognition and by extent on the content fruition. It is not a mere issue of equipment quality or technology generation, but the reception ambiance affects cognition and the emitter has no control over it. In fact, the first step of reception is a sine qua non condition for decoding images and sounds. In regions with poor receiving conditions (in case of air transmissions and mobility) or with narrowband internet (with excessive delays and communication breakdowns), special attention should be payed to this matter, since, together with subjectivity, it is a determinant factor for the construction of meanings.

\subsection{Content production and reception logic}

Besides technical influences on the construction of meanings, in contexts of mass communication and mass culture, the theoretical legacy does not directly face the local nuances. Noteworthy contributions to bridge this lack are the corpus of Martín-Barbero and Nestor Canclini's works for analyzing Latin America phenomena, in which the very particularities of the region are investigated under the prism of cultural hybridism, content production and reception logic. (Cultural hybridism is a useful theory for understanding the vicissitudes of social mechanisms, being one of the Canclini's concerns and is addressed in (2003); whereas several issues related to content production and reception logic are deeply analyzed, in the Latin America context, in (MARTÍN-BARBERO, 1897) and (MARTÍNBARBERO; REY, 2004)).

To some degree, although mass media are considered one of the pillars of modernity, their impacts are not fully understood, mainly if we consider digital potentialities, linking reception and content production in an interactive mode never seen before.

The expression "mass communication" allows several interpretations of what really means a structured process of symbolic transmission and reception. The communication flow is to a certain extent bi-directional: the receiver (viewer in a conventional television experience) "actively" participates in the process. By the understanding of Wendell Johnson's model, the reception context exerts influence on the assignment of meaning. It results in individualized experiences, in a sense that communicating is not only producing and delivering content, but also being aware of the conditions in which the user receives, assimilates and remodels the content in the light of his/her sociocultural horizon. Thompson 
(1995) argues that the receivers have some ability to interfere and contribute to the content in a communication process, even though making use of other media, for instance, telephone calls when watching a live-broadcast program.

\subsection{Interactivity: the much-needed circulation}

With the emergence of digital technologies, the communication process asymmetry tends to be balanced, resulting in a condition closer to the bi-directionality. An example of this is the introduction of interactive applications over TV platforms. By means of such an application, which is provided by an interactive TV service provider, for example, the audience may actively participate and affect the program being exhibited. Still regarding mass media, other examples of interactivity are complementary audiovisual services, such as additional information associated with a program, reality shows with audience vote, playlists, on-air round table discussions and so on. Unfortunately, interactivity applied to educational programs is yet scarce in TV broadcasting portfolios, once the market logic prevails over other social interests.

Conversely, the offer of more content, in one or several media platform, makes some choices possible. The users may "format" their programming by means of a remote control or choose other platform through her or his convergent device. Here someone may argue: Does freedom of choice work in a country with serious lack of literacy and where the media are strongly directed to stimulating consumption or are weakly covered by public policies? Whatever the answer to this question may be, without full interactivity, the flexibility is quite limited and, again, the production and reception contexts are determinant for the construction of meanings, in a sense that it reflects one's sociocultural background.

Despite full interactivity being a certain novelty in mass media communication, it is inherent to content offer in any convergent device or to digital communications in general. In convergent devices, full interactivity is completely natural, in such a way that people do not perceive its presence as an isolate feature. It is intrinsic to digital apps and shapes the individual behavior that each one makes when interacting with such devices.

The current behavior of the media consumer, in terms of demand and customization, also leads to another concept, that of "prosumer". This term was created by Alvin Toffler (1980) and designates a fusion of producer, professional and consumer characteristics. Interactivity is an enabling technology for the existence of prosumers, making people more active in the act of consuming information and new media. The old figure of "viewers" or 
"passive consumers", typical of mass communication, gives way to the prosumer - an active consumer of the digital era.

The behavior of web service consumers, sporadic or immersive users (see, for example, an in-depth view on their cognitive profiles provided by Santaella, 2004), has several implications, which we briefly comment later in subsequent items. In its entirety, the interactivity as a meaningful concept that extrapolates the technical dimension is still a theme of studies. Some efforts in this sense, including semiotic and cognitive issues, have being done, for instance, (BUCY, 2004; DALGAMO et al., 2009; ADAMI, 2013)

\subsection{Media and cultural identity: the audience preferences}

Broadcast TV still assumes a central role in television viewing, although people are combining it with different on-demand services and media. Even considering one of the classical theses that assign to television a certain role in the cultural disestablishment, it is possible to recognize that it contributed to weave the social links of modernity and that regional traditions are included in the television programming (WOLTON, 1996). In Latin America, the example par excellence of such a phenomenon is the "telenovela", a genre that mixes the media innovations and the old narrative structures of the popular culture.

Facing the ability that television has to transform sensitivities and serve as a vector for the construction of imageries and identities in Latin America, it is characterized by a conflicting duality. At the same time that this mass media acts as a mechanism of modeling and deforming people's daily life, it also behaves as an unprecedented mediation factor within the universe of popular culture, by combining world-wide narrative genres with cultural matrices originated in Latin America (MARTÍN-BARBERO; REY, 2004).

Since reality inspires the telenovelas that, in turn, exert influence on the reality, Wolton (1996) believes that television is the first interactive mass media. A very illustrative case of such a circular process is observed in Brazil, where television reaches almost the entire population. The combination of realism and imagery, tradition and invention - quite common in telenovelas - has contributed to integrate millions of individuals in the Brazilian society, regardless literacy levels, regional contrasts and socioeconomic classes.

\footnotetext{
${ }^{5}$ This televisual genre has achieved immense popularity in Latin America. In other regions, for example, in Europe and North America, it is named "soap-opera", but with some differences in format and pathos.
} 
With the advent of digital technologies, a new time of rethinking media impacts arises. More recently, new media and content have introduced other aspect of audience preference, for example, a multimedia content (a short text, news, photo or video) that "goes viral" and "becomes a meme". Similar to remarkable scenes in a TV series or novel episode, a "meme" may represent a common subject shared by many and many people (in the order of millions), contributing to initiate conversations and even to reinforce cultural identity and feeling of belonging. Of course, it is an interpretation of such a complex phenomenon, requiring careful studies as was done with TV content in the 80's and 90's.

Some events and content arouse interests and outline people's preferences, driving content production and enhancing technology acceptance. Besides reducing psychological impairments in terms of technology usage, these factors foster the diffusion of some web apps and the consumption of specific content. Over time, such trends lead people to incorporate new gadgets in their daily life, what has positive and negative impacts. As beneficial consequences, it is possible to mention not only more opportunities for entertainment but also the increase in digital literacy, in handling new technologies for accessing services and acquiring knowledge. As undesired effects are the restriction of access to new sources of information and non-exploitation of the infosphere's knowledge and communication potential, so that people may be confined to a reduced range of content, having no stimulus to discover new perspectives.

Hence, how to make the most of the potential that digital media offer to extend the possibilities of education and social inclusion, besides fostering the socioeconomic development? In this sense, Latin America and other developing regions may follow alternative paths. Digital technologies policies are essential steps towards this direction.

\subsection{When the long tail encounters the global village}

From a socio-technical viewpoint, the communication topology, with variations in the distribution network, has different impacts on the reception modes. For example, broadcasting - especially free-to-air TV - has certain effects on social and political spheres, specifically in terms of identity and cohesion, once a program watched by a large audience creates a common theme for socialization and identity consolidation, as we have already mentioned in the previous topic. Similar effects are observed in internet and social networks, both of which emerged from the dramatic diffusion of digital technologies. The massive use of digital 
technologies and the consolidation of the networked society materialize the McLuhan's envisage of a global village.

An opposite effect is achieved with the content individualization or with the segmentation typical of paid programming, which is directed to specific niches - the so-called narrowcasting. Following this argument to its limit, we have egocasting - a stage in ICT usage in which individualism and subjectivity are the dominant values, taking the personal taste and sole perspective to the last consequences - as envisioned by Rosen in "The age of egocasting" (2005), and considered by some thinkers concerned with the convergence effects over the user's behavior. Paradoxically, the same technologies and conditions fostering individualism produce a contrary effect - the deindividuated behavior, as pointed by researchers in social psychology, since users act anonymously in new media platforms such as internet and social networks.

The very own content diversity enabled by digitization and these behavior trends may be an opportunity to either get in touch with global cultures or offer regional and local content, though the production logic favors the former. Even if it seems paradoxical, and to a certain degree, the new communication formats contribute to reinforce the localism, the notion and feeling of community identity. A consequence of this trend is the so called "glocal concept" - in which the natural opposition between global and local is surpassed by a converged perspective that makes evident this double trend and highlights how they are interrelated and mutually influenced.

Emergent technologies are a key-issue to understand such a phenomenon even though there is some skepticism about identifying clearly the role that the technical dimension performs in this trend. According to Martín-Barbero (1987), the rise of new production technologies, such as compact video cameras spread out in the market, and the diffusion of reception technologies, e.g., parabolic antennas and cable have not modified the production model of conventional TV. However, we can argue that it could be the scenario at the end of the 1980's, before the advent and massive diffusion of digital technologies, in special the internet and smartphones.

An opposite view is been observed as new ICT and content formats are taken into account and new distribution alternatives emerged, such as TV and video over the internet. With the expansion of residential broadband and the entry of new agents into the video market - for example those resulting from the fusion of internet service providers and major content 
producers - , new habits were formed and consolidated at a speed beyond the more optimistic expectations.

According to Anderson (2006), by contextualizing television in the face of the "long tail" market phenomena, some providers of video sites are reaching audience levels close to conventional TV programming, an example is musical videos. This author also emphasizes the phenomenon of popular videos, which are made at low costs and watched daily by thousands of individuals, at a time when people are increasingly accepting new media in their living rooms and consuming new contents. As consequence of this new distribution formats, the trend is to reduce the slot of videos and programs in general, incorporating popular and multicultural thematic, in a manner that the demands of the public - instead of the desires of suppliers - start to prevail.

It may be a great opportunity to provide means for multicultural expression and ultimately to reinforce democracy - before that, to foster intersubjectivity, mainly among people without a voice. Simultaneously, we might interrogate ourselves how to avoid undesired effects due the emergence of all these new technologies. Or yet, how could we prevent problematic changes in individual relationships or even in social interactions whose consequences are completely unimagined?

\subsection{Decisively, a complex process}

In fact, several factors are embedded in the intricacies of a communication process and they express the complexity degree of such a subject. Nevertheless, the unknown and uncertainties are at the core of any attempt to reveal the secrets of an interaction between emitter and receiver, and are elements of its model. We can reasonably relate these aspects with what Melanie Mitchell says in (2009), that a possible measure of the complexity of a system is its Shannon entropy or the "amount of surprise" a message has.

All this complexity requires attention and should be contemplated in policies that contextualize it in each dimension of a socio-technical system - the nowadays communication ecosystem.

\section{UNDERSTANDING MODELS AND SUPPORTING POLICIES}

As we can note, the technological convergence environment presents broad and unprecedented challenges that need to be duly considered in the political, cultural, market and 
regulatory spheres (for example, several issues on this matter are addressed in MANSELL; RABOY, 2011). Underlying factors and conditioners of this scenario are complex, hard to predict and not fully understood, posing difficulties for policy makers and its governance.

Among such factors we can mention: the digitization of content and communication devices; the platform convergence for services and digital media; the diffusion of broad band accesses; media and content globalization; the empowerment of users to produce content; and changes in traditional boundaries between media (video, cinema, television, books, newspapers and magazines, for example), both in distribution and visualization, as in the creation and production. As cutting-edge technologies advance, new market arrangements emerge and changes in users' habits are consolidated, the promises of technological convergence bring also undesired implications. Such implications are diverse in natures: ethical (e.g., privacy), environmental, physical and cyber security, digital and social exclusion, fast obsolescence of technical apparatus and professional capabilities, to name a few. To all these driving forces, wanted and undesired, we can include the cognitive and cultural impacts that new digital technologies may cause.

For example, digital economy capitalizes from the amount of time people stay online. The web design tends to follow a market logic that seeks to get the internet user's attention more and more. Such mechanisms for "attention capture" have induced people to use internetenabled devices more than they would like, provoking some undesired effects as concentration deficits. Besides, the large-scale use of mobile and social apps makes it almost imperative to stay constantly online for accessing the screens and checking messages and posts, often using several screens and multitasking. It implies a continuous information overload and brings changes in cognitive patterns and even some kinds of disorder ${ }^{6}$. Among other consequences, some studies related these effects to a "screen fatigue". Probably this fatigue goes beyond physical symptoms and indicates a possible psychic exhaustion due to long exposure time to digital communication and, ultimately, it may cause the impoverishment of people's inner lives.

\footnotetext{
${ }^{6}$ Eric Topol (2012), a digital medicine researcher, and Tim Wu (2016), a scholar of media and telecom law, have characterized this effect as "homo distractus" - the difficulty to maintain attention in one thing or task, due to some people being compulsively checking their gadgets.
} 
Reacting to the consequences of these digital trends and impacts, a collaborative work was published in 2010 with the title "slow media manifesto" "appropriate reactions to this media revolution are to be developed and integrated politically, culturally and socially". By defining the main concept and intention of such "reactions", we find in the manifesto: "Like 'Slow Food', Slow Media are not about fast consumption but about choosing the ingredients mindfully and preparing them in a concentrated manner". The manifesto emphasizes sustainability, social media and quality in production and reception of media content, among other issues.

Of course, all these changing factors, both positive and negative, need to be considered in detail, based on societal debates and reflections, coordinated planning actions and formulations of specific policies. Technical issues - innovating and radically transforming the processes of creation and distribution of content - and market forces, with the logic of production acting locally and globally, significantly transform the relational bases and the performance balance of all players involved in this ecosystem.

According to Terry Flew, in his considerations about the convergent media policy moment (2012), there is consensus that the confluence of digital technologies, cultural and economic globalization, and the market globalization of media content has impacted the structure of mass media communication, characterizing a media environment that he named "post-policy".

In Brazil, the CGEE (Center for Management and Strategic Studies) presented an international overview of the technological convergence approach, aiming to provide orientations for scientific and technological policies applicable to this scenario (2008). Despite this work focusing nanotechnology as a central element of technological convergence, some suggested guidelines are general and extensible to other technologies.

Thus, among the highlights in the aforementioned study (CGEE, 2008), two of them highlight aspects that we intend to bring to this reflection. First, the need to consider the social dimension of technological convergence and its impacts. Moreover, some initiatives in this field have among their objectives to support the understanding of the social, ethical, environmental, health and safety dimensions. Second, amid the race and the promises of the

\footnotetext{
7 The Slow Media Manifesto (http://en.slow-media.net/manifesto). A reflection on its impact on different countries, cultures and disciplines is shown in (DAVID, 2015).
} 
technological convergence, many experts question whether public policies are being developed and implemented to serve the interests of humanity.

Undoubtedly, several issues need to be considered in formulating and evaluating ICT policies. Towards fostering digital inclusion, by way of illustration, policy makers should consider not only the provision of physical access to new technologies but also means to overcome accessibility and intelligibility hindrances in order to provide isonomy of access to all social, economic and cultural segments of the population. An approach to overcome such limitations and bringing "excluded" people into digital era is shown in (HOLANDA; DALL'ANTONIA, 2006).

From our point of view, comprehensive communication models broaden the understanding of the factors associated with the challenges mentioned up to this point, adding inputs for the formulation of strategies, regulations and plans for scientific and technological development. Such models reveal features and unexpected aspects, at least initially, bringing to the analytical and reflexive sphere aspects associated with communication and information, both in the technical field and in the complex domains of cognition, intersubjectivity, trends in content creation and fruition, media and equipment market logic, as well as control and political domination. The inputs provided by this approach may be used in line with the guidelines for a sustainable development, mainly in terms of conciliating ethical and social commitments with technological innovations - on this issue, see for example (VON SCHOMBERG, 2011).

However, the act of formulating practical guidelines for digital policies is not a simple activity and cannot be summarized in a standard set of recommendations. Plans and guidelines depend on the technological and socioeconomic context in which policies will be inserted, the political moment and the whole conjuncture that legitimizes and empowers a specific policy. The present reflection aims only at highlighting key issues that should be considered by policy makers - in ethical, technological, cultural and socioeconomic dimensions, to mention a minimum core -, when the balance of forces at play and sustainable solutions are intended.

\section{FINAL REMARKS}

The understanding of the factors that affect all the dimensions of this convergent scenario is facilitated by models that describe the stages of a communication process 
considering the technical and social dimensions, with all the influence factors - of political, economic, cultural and cognitive nature. In addition, the model should consider the complexity of the phenomena involved, such as the circularity of information enhanced by interactivity, and the various impacts prompted by new technologies. The approximation and fluid interchange between diverse fields of knowledge is fundamental for an in-depth view of all the impacts and challenges faced in this scenario.

This broad vision seems to be decisive in the generation of recommendations for media and communication policies in the digital age. It is necessary to transcend patterns, because it is about dealing with the unknown or, at least, with what is in constant transformation. Policy makers and researchers should be concerned not only with technical or industry/market issues of convergence but also with social, cultural and psychological ones. Several impacts due to cutting-edge technologies and changes in individual behavior facing new media must be carefully considered, mainly regarding education digital services, devices and internet content for children, and apps for older and younger generations, to mention just a few of them.

Far from presenting a new communication model or concrete recommendations for digital technology policies, here we have outlined an analytical panorama and some initial reflections that allow us to broaden the vision on complexities of the technological convergence, a scenario of the present times: "post-modern", "post-policy" and, unfortunately, still "pre-sustainable". The very complexity of the factors and impacts indicated here requires further analysis in specific studies and papers. Such work is in progress.

\section{ACKNOWLEDGMENTS}

The authors are grateful to the Brazilian National Council for Scientific and Technological Development (CNPq) for the support, in the form of institutional capacitation scholarship, which allowed this work to be carried out.

\section{REFERENCES}

ADAMI, Elisabetta. A social semiotic multimodal analysis framework for website interactivity. National Centre for Research Methods/University of London, working paper, 2013. 
ANDERSON, Chris. The long tail: do mercado de massa para o mercado de nicho. Rio de Janeiro: Elsevier, 2006.

BAR, François; SANDVIG, Christian. US communication policy after convergence. Media, Culture \& Society, v.30, n.4, p. 531-550, 2008.

BERGSON, Henri. Introdução à Metafísica. In: Os Pensadores, v. XXXVIII, trad.: Silva, F. L. São Paulo: Abril, 1974.

BUCY, Erik P. Interactivity in Society: Locating an Elusive Concept. The Information Society, v.20, n.5, p. 373-383, 2004. doi: 10.1080/01972240490508063

CANCLINI, Nestor G. Culturas híbridas. Estratégias para entrar e sair da modernidade. São Paulo: Edusp, 2003.

CGEE - Centro de Gestão e Estudos Estratégicos. Convergência tecnológica. Brasília: CGEE, 2008.

DALGARNO, Barney, KENNEDY, Gregor; BENNETT, Sue. Using brain imaging to explore interactivity and cognition in multimedia learning environments. In: Proc. of 21 st Annual Conf. of the Australian Computer-Human Interaction Special Interest Group (CHISIG) of the Human Factors and Ergonomics Society of Australia. New York, USA: ACM, p. 405-408, 2009.

DAVID. Sabria. The Slow Media Manifesto and Its Impact on Different Countries, Cultures, and Disciplines. Acta Univ. Sapientiae, Social Analysis, v.5, n.1, p. 107-112, 2015.

FELL, Elena. Beyond Bergson: the ontology of togetherness. Empedocles European Journal for the Philosophy of Communication, v.1, n.1, pp. 9-25, 2009. doi: 10.1386/ejpc.1.1.9/1

FLEY, Terry. The Convergent Media Policy Moment. Institute for Culture and Society Occasional Paper, v.3, n.3, 2012. doi 10.4225/35/57a9662ef7e8b

GLEICK, James. The information: a history, a theory, a flood. Harper Collins Publishers, 2011.

HINTON, Perry. The cultural context of media interpretation. In: Kotthoff, H. \& Spencer-Oatey, H. (eds.). Handbook of Intercultural Communication. Berlim: Mouton de Gruyter, p. 323-339, 2007.

HOLANDA, Giovanni M.; ÁVILA, Ismael M.; MARTINS, Ricardo B. Mapping users' perspectives in outlining social impacts from digitalization of terrestrial TV in Brazil. Telematics and Informatics An Interdisciplinary Journal on the Social Impacts of New Technologies, v.25, n.1, 2008. doi: 10.1016/j.tele.2006.01.001

HOLANDA, Giovanni M.; DALL'ANTONIA, Juliano C. An Approach for e-inclusion: Bringing illiterates and disabled people into play. Journal of Technology Management \& Innovation, v.1, n. 3, 2006.

JOHNSON, Wendell. The spoken word and the great unsaid. The quarterly Journal of Speech, 37 (4), 1951.

LAURETH, Waleska C. Technological convergence, education and work: from the social global discourse to regional challenges (in Portuguese). Revista da ABET, v.13, n.2, jul-dez 2014.

LÉVY, Pierre. As tecnologias da Inteligência - o futuro do pensamento na era da informática. São Paulo: Ed. 34, 1993.

MANSELL, Robin. Media convergence policy issues. Oxford Research Encyclopedias, 2016. doi: 10.1093/acrefore/9780190228613.013.62

MANSELL, Robin; RABOY, Marc (Eds.) The handbook of global media and communication policy. Wiley-Blackwell, 2011.

MARTÍN-BARBERO, Jesús. De los Medios e las Mediaciones: Comunicación, cultura y hegemonia. Barcelona: Gustavo Gili, 1897

MARTÍN-BARBERO, Jesús; REY, Germán. Os exercícios do ver: hegemonia audiovisual e ficção televisiva. Trad: Gorender, J. São Paulo: Ed. Senac, 2004 
MATTELART, Armand; MATTELART, Michèle. História das teorias da comunicação. São Paulo: Edições Loyola, 1999.

MCQUAIL, D.; WINDAHL, S. Communication models - For the study of mass communication. New York: Routledge, 1993.

MITCHELL, Melanie. Complexity: a guided tour. New York: Oxford University Press, 2009.

NARULA, Uma. Handbook of Communication - Models, perspectives, strategies. Delhi: Nice Printing Press, 2006.

OFCOM. Communications Market Report 2017 - United Kingdom. London: Ofcom, 2017.

ROSEN, Christine. The age of egocasting. The New Atlantis - A Journal of Technology \& Society, 7, p. 51-72, 2005.

SANTAELLA, Lucia. Culturas e artes do pós-humano - da cultura das mídias à cibercultura. São Paulo: Paulus, 2003.

SANTAELLA, Lucia. Navegar no ciberespaço - o perfil cognitivo do leitor imersivo. São Paulo: Paulus, 2004.

SHANNON, Claude; WEAVER, Warren. The mathematical theory of communication. University of Illinois Press, 1949.

THOMPSON, John B. The media and modernity: a social theory of the media. Stanford: Stanford University Press, 1995.

TOFFLER, Alvin. The third wave: The classic study of tomorrow. Bantam Books, 1980.

TOPOL, Eric. The Creative Destruction of Medicine: How the Digital Revolution Will Create Better Health Care. Basic Books, 2012.

VON SCHOMBERG, René. Towards Responsible Research and Innovation in the Information and Communication Technologies and Security Technologies Fields. Luxembourg: Publications Office of the European Union, 2011.

WIENER, Norbert. The human use of human beings. The riverside Press, 1951. (Br. Translation: Cibernética e sociedade: o uso humano de seres humanos. São Paulo: Cultrix, 1954)

WOLTON, Dominique. O elogio do grande público: uma teoria crítica da televisão. Ed. Ática, 1996.

WU, Tim. The Attention Merchants: The Epic Scramble to Get Inside Our Heads. New York: Knopf, 2016.

ZEGARAC, Vladimir. A cognitive pragmatic perspective on communication and culture. In: Kotthoff, H. \& Spencer-Oatey, H. (eds.). Handbook of Intercultural Communication. Berlim: Mouton de Gruyter, p. 31-53, 2007.

\section{Original recebido em: 11 de outubro de 2017}

Aceito para publicação em: 26 de setembro de 2018

Giovanni Moura de Holanda

MSc degree in Electrical Engineering, area of Electronics and Communications (Unicamp, 1992), and BSc degree in Electrical Engineering (UFPB, 1983). Researcher and consultant in Information and Communication Technologies. He was research fellow (CNPq) at CTI Renato Archer (2016-2018). Currently he is data scientist at FITec - Technological Innovations, Brazil. 
PhD in Information Technology (USP/POLI, 2013) and MSc degree in Quality (Unicamp, 2002). Researcher in software process and policy evaluation. Currently she is in charge of the division of institutional support and coordinator of the research project "poli.TIC", at CTI Renato Archer.

\section{()ㅇㅇ}

Esta obra está licenciado com uma Licença

Creative Commons Atribuição-NãoComercial-CompartilhaIgual 4.0 Internacional 